\title{
How to Improve the Passing Rate of English for Self-taught Examination
}

\author{
Caiyan Jiang \\ Department of Public Foreign Language Teaching \\ Yantai Nanshan University \\ Longkou, Shandong, China
}

\begin{abstract}
In the process of continuous development and improvement of economic globalization and informatization in social life, English, as an international language, increasingly shows a pivotal position in various countries and national information, culture, science and technology exchanges. Learning English well has become a stated target of most people. At the same time, the society demands more and more on college students' English proficiency, and the College English proficiency test is an index of the college students' English level. This thesis puts forward the author's point of view on how to improve college English test passing rate based on the actual work.
\end{abstract}

Key words-English Test; self-taught Examination; teaching at different levels

\section{INTRODUCTION}

School's attitude to self-taught examination and how to organize and promote college students' English learning determine whether or not it can create a good atmosphere for the exam-oriented English. Whether or not it can mobilize the enthusiasm of students and teachers. So to improve the pass rate cannot rely on unilateral reason, but the results of a multi-factor interaction. The blame on students' bad grades or the poor evaluation on teachers' teaching unilaterally is not the consideration from reality. So this thesis studies how to improve English self-study test passing rate from the following aspects.

\section{VOCABUlaRY MEMORY STRENGTHENING}

This course focuses on the English basic vocabularies and grammars. The main purpose of the course is to develop the reading ability. Vocabulary review based on vocabulary syllabus, and the phrases must be mastered expertly.

\section{A. The Process of Memory}

Firstly, having a general look at vocabularies that syllabus requires our grasping for a few times. "Verb noun - adjective - adverb - preposition", "Conjunctions pronoun-Quantifier ". (Verb is the key, it requires to read, write and use, seeing it can know its meaning and collocation instantly)

\section{B. Memory Method}

1) Classification Comparison: Memorizing a group of congeneric words, when meeting one of the words, the group of words appears in the mind, the efficiency can be improved greatly.

e.g. Economy/ economic/ economical/ economically

cat/dog/ cattle/ sheep/horse/ chicken/ monkey

red/green/yellow/ purple/blue

It can also transfer mechanical memory into understanding memory through the method of the discrimination between synonyms and antonyms, homophones, part of speech conversion words of comparison and induction, which can enhance the memory traces, improve the memory efficiency.

e.g. buy/purchase, able/capable

negative/positive

increase/decrease

2) Memory Combined with Context Of Situation: Putting the words in the context can people really understand its exact meaning, reciting the words with abstract concept in the specific phrase, sentence or text can people understand the meaning of the words. In this way it is easy to remember and have a better understanding of its use in the specific language environment. Public English self-study exam has its particularity, examinees can memorize words in the text combined with the self-teaching materials based on the mastery of words and the familiar text.

3) intensive memory repeating: According to the law of forgetting, it can enhance the memory effect in the plans to "reproduce" to consolidate the study of English words. The law of forgetting is firstly forgetting fast then slowly, the material just remembered forget fastest in the first few hours. If without repetition within four to seven days, memory will be suppressed, even completely disappear.

Grammar must grasp and master fully. It not only requires the syntax content of the review (Vol. 2), but also review (Vol. 1) about the syntax content, specifically including: verb tense and voice, non-finite verb, subjunctive 
mood, attributive clause, noun clauses, adverbial clauses, comparison, word order, subject verb agreement, emphasizing sentences, basic sentence patterns; verbs and compound sentence which is very important.

\section{THE QUALITY OF TEACHING IMPROVEMENT AND STUDENTS' LEARNING ENTHUSIASM AROUSING}

Through the understanding above, self-taught English mainly includes cognition of each grammar and memory of the words. Aiming at the teaching goal, the contest between teaching and learning unfolds. Under the standards of the new curriculum, the key of whether or not classroom teaching can put the three-dimensional targets of "knowledge and skill, process and method, emotion, attitude and value view" into practice is whether or not teachers can handle the relationship of "teaching and learning" correctly.

Teacher's teaching is a kind of art, it requires the teachers to teach students in accordance with their aptitude, according to different types of students, different levels and different contents of teaching materials to express, passionate, vivid contents, and from easy to deep teaching in different ways. According to the characteristics of self-taught English textbook content, we can use the following two kinds of teaching methods.

\section{A. The Method of Grammar Translation and Its Application}

The method of grammar translation has a long history, it is a method to learn the grammar system of language as a center. Harmer (1983) argues that it is fundamental for any language learners to master grammar. Alexander (1988) pointed out that the root cause of mastering any kind of language is the grammar. He thinks that grammar learning is a shortcut to learn any languages. Because grammar is a summary of the structure and rules of a language. Foreign language learning also can find the same law. By way of analogy, widely comparing to improve learning efficiency. But the disadvantage is that learners will learn the dumb English eventually, cannot get the English as a medium to carry out a professional communication skills.

\section{B. Communicative Approach and Its Application}

Communicative approach emphasizes the importance of students; the task of teachers is to guide students to participate in the classroom activities. It emphasizes situational teaching.

It gives students a real life scene, and cultivates their practical languages and communication skills. In the classroom, it often uses heuristic and discussion to achieve the interaction between teachers and students. The purpose of language training is to master English communicative competence. Students only have the ability to communicate in English can they cope with the communication needs in daily life in the English speaking countries, and can communicate with their foreign counterparts in their professional fields. Of course, the communicative approach and the grammar translation method complement each other.
With a certain grammatical basis, it can play the communicative function more effectively.

Of course, classroom teaching is a two-way interactive activity between teachers and students, not a person's activity. Teachers can judge students' needs according to their expressions and responses, so that students can really integrate into the classroom. It stimulates students' interest in learning English. Arranging the recess, so that the teacher's pleasure of teaching can lead students' happiness. At the same time, this thesis introduces the characteristics of College English learning, and helps students to change their concept of learning and adjust their learning strategies. It is not enough to finish the homework after class, students should learn to develop the good habit of self-study.

In addition to enable students to take the initiative to learn and love learning, it is needed to create a good learning atmosphere. A place where you can learn English at any time is needed. For example, English corner, English speech contest, reading contest, dictation contest and so on. Making students feel the pleasure of learning English can improve their confidence in learning English.

\section{MANAGEMENT OF STUDENTS LEARNING STRENGTHENING}

To have a good style of study, teaching style. Management plays a key role. Students are the main factors to improve the level of English teaching. Other conditions are good students, no pressure and power will be less effective. College students attitude towards English learning is very different, and some students in order to get an undergraduate certificate, there is a clear learning objectives. , there are some students know to pass the exam to get a certificate, but because of weak foundation, learning is blind. Thought is also very lax. For this part of the people, to overcome the negative "and so on, by" psychological help them find a way different from the middle school learning methods. Form good habits.

For the students who are poor in this part of the textbook, teachers should take a distinction between them and manage them in groups. Students who do well as the group leader leading others to learn. Their difficulty is nothing more than to understand and remember the words and understand the text. For the section of words, teacher can explain 20 words a day and send pictures and recordings to the students. This group of words can be from the classification mentioned above, and also can be in accordance with the rules of the first letter change (such as the A-Z words) so as to avoid the brain fatigue. The section of the text can be read in the case of words, and be sent to the team leader so as to achieve the understanding of the text in the process of recording. Therefore, learning English is a long-term process, we must take the initiative to let this part of the students participate in the process so as to achieve teaching objectives. 


\section{THE INTRODUCTION OF COMPETITIVE MECHANISM TO CREATE A BETTER FUTURE}

In order to stimulate students' learning enthusiasm and improve the teaching level. Firstly, schools can organize the college counselors, head teachers and teachers work together to reward those who passed the self-taught examination each year, so that everyone can have the spirit of cooperation, catch condominium together and do his duty. Between students and students, class and class to form a good competitive atmosphere.

\section{SElF-TAUGHT EXAMINATION COUNSELING}

"Practice is the sole criterion for testing truth", one of the most important section in English teaching is the test of English as a foreign language. It is not only a measure of one of the effective tools for the English teaching effect, and is an important medium for testing students in English learning. It reflects the reform of College English teaching content, teaching concept, teaching means and methods of advancing the process. Getting good grades in English examination is the mark of every students expecting to learn something. So, how to do a full preparation through the early efforts for examinations in the later exams so as to improve English grades and show their English ability, the following points will make full description in details completely.

\section{A. Explaining Papers for Last Exams, and Create a Test Database Based on the Papers}

At least two sets of test questions for students to practice. Time can also be prepared for the special practice. For example, students are not able to grasp the virtual tone, inversion, non-infinite verb and other grammatical structure. Then the grammar is divided into special training, complete type of special training, reading practice, the word and the deformation of special training, translation training, etc. Anyhow, the university English teaching concept and mode is not conservative, only through the improvement and innovation can students truly achieve grade examination of higher level rate.

\section{B. Strengthening the Cultivation of Translation and}

Reading Ability, which Occupies an Important Position in English Proficiency Test

In English self-study exam, translation and reading account for a large proportion of scores and are very important, in the meanwhile, they can open a gap between different scores. Strengthening the training of the two aspects can help students with a more solid foundation achieve better grades in the exam. The ability of translation, first of all is to guide students have a grasp of the whole text in text learning, and master the sentence translation skillfully; secondly, it can be grouped and then let the group leader distribute the recordings to members of the group to help them understand the text better, and seize useful information. For reading:

1) Formulating a Reading Plan and Strengthen the Reading Training: First, students should overcome difficulties, make self-suggestion, and strengthen confidence in English reading. In the preparation, they need to develop detailed and practical reading plan to ensure the daily English reading time, accumulate vocabulary, and improve the reading speed and reading efficiency through repeated training. It is suggested that the examinees in the daily training of reading pay attention to the following aspects: grasping the theme; three key plots and background knowledge in order to have a better understanding of the intention of writing; realizing the enlightenment and educational experience the subject gives us; developing the habit of reading the outline; summarizing the main content of the reading materials; clarifying the main characters' name, identity, main activities, psychological characteristics and their relationship; understanding the difficult language points or the main statement related to the theme, which is often the topic eye.

2) Being Familiar with the Examination Questions and Summarizing the Answer Skills: Reading methods and skills are decided by the examination questions and requirements. The majority of the candidates need to understand the requirement and characteristics of the reading multi-choices, and summarize some methods to solve problems in training. Here we can choose several question types to have a talk about test-taking strategies combined with reading.

a) The question of facts and details. This topic mainly examine the candidates' abilities to grasp the theme of related facts and details of the test, and it involves a lot of time, places, persons, numbers, and the reasons of the specific content. The answers to these questions can often be found directly in the text. So long as the candidates are a little more careful coupled with a certain reverse thinking, mathematical calculations and simple analysis can they get correct answers. When candidates answer, the question should be located in the original text through the key words of the title, judge the details of the subject related to the theme and exclude redundant information. To sort out the details and the main thrust of the relationship carefully, such as primary and secondary, cause and effect, contrast, time and so on; paying attention to examples, lists, (instructions $X$ pronouns, references and special punctuation marks, etc.

b) The question of main idea. This kind of topic examines the examinees' general understanding ability to the article topic, the central thought as well as each paragraph. The theme of the subject will generally present in the first sentence or the first paragraph directly reflected, it is also possible that it is shown after the statements of fact in the middle or at the end of the article. Candidates at the same time should be good at summarize the full text, it also is suggested to integrate the key sentences with the gist of the integration, which is often able to reflect the main points of the text fully.

c) The question of viewpoints and attitudes. The questions text examinees' ability to understand and appreciate the writer's opinion, attitude, writing intention and the emotional tendencies of a fact or phenomenon. 
Usually in the argumentative articles, some authors will reveal his attitude, affirmation, denial or doubt for a phenomenon, while some authors only evaluate a phenomenon objectively. Candidates need to distinguish the author's point of view, the viewpoints of the main characters in the articles, and the views of readers and the public and etc. The verb and adjectives in the process of reading to express the views and attitudes of the author should be paid special attention to, some negative structure, in particular, should pay attention to rhetorical questions of the text and anti-expression.

d) The question of word meaning comprehension. This kind of question is aimed to examine the candidates' ability to understand the meaning of the key words and the pronouns as well as the key sentences in the article. Candidates' answers requires an understanding of context, according to the hint of problem to position to the original passage, having a clear master of the main idea, checking the test vocabulary or sentence context again, and finding out related cues or hints of language. By examining the meaning of a word or sentence, meaning is often found out of context words synonyms or antonyms and what the pronoun refers to are often appearing in the ten days before or after the sentence. And paying attention to the keywords of the conversion of part of speech and morphology changes, such as some words appear in the forms of verb in the original text, while in the exam are available in the form of a noun.

e) The question of reasoning and judgment. This type of topic mainly examines the candidates' abilities of speculating its implied meaning based on the sentence facial meaning of the article. This kind of title is a little difficult, when meeting some questions related to details, the candidates should not overgeneralize them to take the article details as conclusion, resulting in unnecessary loss.

\section{CONCLUSION}

Anyway, the most important is, teachers should understand students, trying to enter their inner world, in the care of their academic achievements at the same time paying attention to their self-esteem, self-confidence. With teachers' emotions to ignite students' passion of English learning, making the students transfer from the "want me to learn" to "I want to learn". Adhere to the principle of not giving up any one to make progress together. At the same time, in English teaching, in order to improve college English selfstudy exam passing rate, the implementation of the individualized education based on hierarchical teaching idea and the way is one of the magic key to improve the passing rate, but also for the best way to teaching mode of improvement and innovation.

\section{REFERENCES}

[1] Harmer $\mathbf{J}$.The practice of English language Teaching [M].London: Longman. 1983.
[2] Wang Wang Hanlan,, "education", [M], the people's education press, 1989.

[3] Han Chun. "College English graded teaching practice" [J]. Journal of Ningbo Institute of education, 2008. 